\title{
Effects of propofol versus sevoflurane on cerebral oxygenation and cognitive outcome in patients with impaired cerebral oxygenation
}

This article was published in the following Dove Press journal:

Therapeutics and Clinical Risk Management

18 January 2016

Number of times this article has been viewed

\author{
Jun-ying Guol,* \\ Jie-yu Fangl,* \\ San-rong $X u^{2}$ \\ Ming Wei' \\ Wen-qi Huang'
}

'Department of Anesthesia, the First Affiliated Hospital, Sun Yat-sen University, Guangzhou, Guangdong,

${ }^{2}$ Department of Anesthesia,

Zhangzhou Municipal Hospital of

Fujian Province, Zhangzhou, Fujian,

People's Republic of China

*These authors contributed equally to this work
Correspondence: Wen-qi Huang Department of Anesthesia, the First Affiliated Hospital, Sun Yat-sen University, 58 Zhongshan Road II, Guangzhou, Guangdong 510080, People's Republic of China Tel/fax +86202882 3388

Email wenqihuang2015@sina.com
Background: Postoperative neurocognitive dysfunction induced by anesthetics, particularly in elderly patients with impaired oxygenation, is a common complication of surgery and is eliciting increased interest in clinical practice. To investigate the effects of anesthetics on neurocognition, we compared the effects of propofol versus sevoflurane on cerebral oxygenation and cognitive outcome in patients with impaired cerebral oxygenation undergoing general anesthesia.

Methods: Sixty-three patients with impaired cerebral oxygenation (jugular venous bulb oxygen saturation $\left[\mathrm{SjvO}_{2}\right]<50 \%$ ) or cerebral blood flow/cerebral metabolic rate of oxygen $\left(\left[\mathrm{CBF} / \mathrm{CMRO}_{2}\right] \leq 15 \%\right)$ undergoing elective abdominal surgery were randomly allocated into propofol group (group P) or sevoflurane group (group S). The clinical parameters and jugular venous bulb blood gas analysis were monitored throughout the surgical procedure. Cognitive function was assessed with the mini-mental state examination and Montreal Cognitive Assessment at day 1 and day 7 following surgery. S100 $\beta$ protein in plasma was measured using enzyme-linked immunosorbent assay.

Results: The $\mathrm{SjvO}_{2}$ increased during anesthesia induction and surgery when compared to baseline but had no significant difference between group $\mathrm{P}$ and group $\mathrm{S}$. When compared to baseline, the $\mathrm{CBF} / \mathrm{CMRO}_{2}$ was increased only at the end of surgery and extubation in group $\mathrm{P}$; however, the $\mathrm{CBF} / \mathrm{CMRO}_{2}$ in group $\mathrm{S}$ was increased during anesthesia induction at 1 hour, 2 hours, end of surgery, and extubation. Furthermore, the $\mathrm{CBF} / \mathrm{CMRO}_{2}$ in group $\mathrm{S}$ was significantly higher than that in group $\mathrm{P}$ during anesthesia induction at 1 hour, 2 hours, and end of surgery. S100 $\beta$ protein did not significantly change at extubation and 1 day after surgery in both groups when compared to baseline. There was no significant difference in mini-mental state examination and Montreal Cognitive Assessment scores between group P and group S at all time points.

Conclusion: Sevoflurane showed similar effects in postoperative neurocognitive function as propofol but could improve cerebral oxygenation in patients with impaired cerebral oxygenation.

Keywords: saturation, postoperative cognitive dysfunction, propofol, sevoflurane

\section{Introduction}

Postoperative cognitive dysfunction (POCD) is a common complication following surgery. ${ }^{1,2}$ The incidence of POCD in the population undergoing noncardiac surgery has been reported to be as high as $9.1 \%-17 \%$ at day 7 following surgery. ${ }^{3,4}$ Increasing age has been reported to be associated with higher risk of POCD, and documented POCD lasting 3 months has been reported to be $12.7 \%$ in elderly patients who usually have preexisting impairment of cerebral oxygenation before surgery. ${ }^{5}$ These studies suggest that preexisting impairment of cerebral oxygenation may be a factor in deteriorating POCD; however, the mechanism is unclear. 
A recent study in animals indicated that long-term administration of isoflurane, exceeding 4 hours, may induce cognitive impairment by reducing the $N$-methylD-aspartate receptor subunit NR2B and the phosphorylation of extracellular signal-regulated kinase $1 / 2 .{ }^{6} \mathrm{~A}$ previous clinical study also indicated that optimizing anesthetics and monitoring cerebral oxygenation could reduce POCD in older patients. ${ }^{7}$ These studies suggest that anesthetics may play a vital role in POCD by changing the cerebral oxygenation. Propofol and sevoflurane are commonly used anesthetics for sedation in general anesthesia, and their effects on POCD have raised the concerns of researchers. It was reported that, when compared to sevoflurane, higher dosage of propofol can further decrease cerebral blood flow (CBF), ${ }^{8}$ which has been, in combination with cerebral oxygenation saturation, used to assess POCD in patients undergoing valvular heart surgery. ${ }^{9}$ However, whether propofol and sevoflurane affect intraoperative cerebral oxygenation and further affect postoperative outcomes in nonheart surgery patients is unknown. In this study, sevoflurane or propofol was applied to different patients with preexisting cerebral oxygenation impairment in order to investigate the effects of propofol and sevoflurane on the cerebral oxygenation during general anesthesia and the postoperative cognitive outcomes.

\section{Methods}

The experimental protocol was approved by the local research ethics committee (number 324, Sun Yat-sen University, 2012), and written informed consent was obtained from the patients. The inclusion criteria were physical status of I-III according to American Society of Anesthesiologists, age range of 40-75 years, presenting for elective abdominal surgery, and predicted surgery time $\geq 2$ hours. Exclusion criteria were a history of cerebral vascular disease, preoperative cognitive dysfunction (illiterate group $\leq 17$, primary and secondary school group $\leq 20$, and junior high school and above group $\leq 24$ ) assessed according to mini-mental state examination (MMSE), which is the most commonly used tool to screen cognitive function, language barriers, severe hearing, and visual impairment affecting cognitive function scores.

All patients $(n=63)$ were administrated with jugular bulb catheterization and blood gas analysis was performed, including jugular venous bulb oxygen saturation $\left(\mathrm{SjvO}_{2}\right)$ and cerebral blood flow/cerebral metabolic rate of oxygen $(\mathrm{CBF} /$ $\mathrm{CMRO}_{2}$ ). The $\mathrm{SjvO}_{2}$ was measured with blood gas analysis of blood samples from jugular venous bulb, $\mathrm{CBF} / \mathrm{CMRO}_{2}$ was calculated by the equation:

$$
\begin{aligned}
\mathrm{CBF} / \mathrm{CMRO}_{2}= & 100 /\left(1.34 \times \mathrm{Hb} \times\left[\mathrm{SaO}_{2}-\mathrm{SjvO}_{2}\right]\right. \\
& \left.+0.003 \times\left[\mathrm{PaO}_{2}-\mathrm{PjvO}_{2}\right]\right)
\end{aligned}
$$

Where $\mathrm{Hb}$ is hemoglobin, $\mathrm{SaO}_{2}$ is arterial oxygen saturation, $\mathrm{PaO}_{2}$ is arterial partial pressure oxygen, and $\mathrm{PjvO}_{2}$ is jugular venous partial pressure of oxygen.

Patients with decreased cerebral oxygenation (desaturation) defined as $\mathrm{SjvO}_{2}<50 \%$ were randomly allocated into propofol group (group $\mathrm{P}, \mathrm{n}=32$ ) or sevoflurane group (group $\mathrm{S}, \mathrm{n}=31$ ). In group $\mathrm{P}$, propofol target-controlled infusion was applied for induction and programmed with the pharmacokinetic parameters of Marsh to a preset plasma concentration of propofol at $4.0 \mu \mathrm{g} / \mathrm{mL}$. In group $\mathrm{S}$, patients were sedated via volatile induction and maintenance technique (sevoflurane $2 \%-4 \%$ at end-tidal concentration) by tidal volume. When patients lost consciousness, fentanyl $(3 \mu \mathrm{g} / \mathrm{kg})$ and rocuronium $(0.6 \mathrm{mg} /$ $\mathrm{kg}$ ) were administered before tracheal intubation. Anesthesia was maintained with propofol $(2-3 \mu \mathrm{g} / \mathrm{mL}$ in plasma) and remifentanil $(0.1-0.3 \mu \mathrm{g} / \mathrm{kg} / \mathrm{min})$ for group $\mathrm{P}$, and sevoflurane ( $1 \%-3 \%$ of end-tidal concentration) inhalation and remifentanil $(0.1-0.3 \mu \mathrm{g} / \mathrm{kg} / \mathrm{min})$ for group $\mathrm{S}$, respectively. Propofol and sevoflurane were adjusted to keep Narcotrend value between 40 and 60. Fentanyl $(1 \mu \mathrm{g} / \mathrm{kg})$ was administrated in both groups.

Patients were mechanically ventilated to maintain the end-tidal carbon dioxide $\left(\mathrm{CO}_{2}\right)$ tension between $4.7 \mathrm{kPa}$ and $5.5 \mathrm{kPa}$. Routine monitoring included invasive measurement of systemic blood pressure, heart rate, electrocardiogram, and pulse oxymetry. Blood samples in jugular venous bulb were taken at baseline, before anesthesia induction, after tracheal intubation, every hour during surgery, at the end of surgery, and at tracheal extubation for analysis of blood gas, oxygen saturation, and then calculation of $\mathrm{CBF} / \mathrm{CMRO}_{2}$. The $\mathrm{S} 100 \beta$ protein was measured using enzyme-linked immunosorbent assay, according to the manufacturer's instructions. The Montreal Cognitive Assessment (MoCA) and MMSE were used to assess the cognition of patients, according to the guidelines. Estimated blood loss and amount of fluid or blood administered during the surgery were also recorded.

\section{Trial registration}

NCT01757561 (https://www.clinicaltrials.gov/ct2/results? term $=$ NCT01757561 \& Search=Search).

\section{Statistical analysis}

Statistical analysis was performed using SPSS for Windows 19.0 (IBM Corporation, Armonk, NY, USA). Continuous 
variables were presented as mean \pm standard deviation [SD], and categorical variables were presented as frequency. Serial changes in cardiovascular $\mathrm{SjvO}_{2}$ were analyzed using repeated measures analysis of variance. $P<0.05$ was considered to be statistically significant.

\section{Results}

\section{General information}

There was no significant difference between the two groups in general information, including age, gender, weight, and disease history (Table 1 , all $P>0.05$ ). Furthermore, there was no significant difference in anesthesia time, surgical time, fluid infused during surgery, blood transfused, urine output, or blood loss between the two groups (Table 2, $P>0.05$ ). There was no significant difference in the administrated dosages of fentanyl, remifentanil, or morphine between the two groups (all $P>0.05$ ) except the dosage of norepinephrine, which was not used in group P (Table 2).

\section{Cognitive function}

As shown in Table 3, the MMSE scores at baseline and at day 1 and day 7 following surgery were similar and there was no significant difference at different time points between the two groups $(P>0.05)$. Furthermore, the MMSE scores were not significantly different between group $\mathrm{P}$ and group $\mathrm{S}$ at all time points (all $P>0.05$ ). The MoCA scores displayed similar changes with MMSE, and there was no significant difference between the two groups at different time points $(P>0.05$; Table 3$)$.

\section{$\mathrm{SjvO}_{2}$ and $\mathrm{CBF} / \mathrm{CMRO}_{2}$}

In both group $\mathrm{S}$ and group $\mathrm{P}$, the $\mathrm{SjvO}_{2}$ increased during anesthesia induction at 1 hour, 2 hours, and the end of surgery. In group $\mathrm{S}$, the $\mathrm{SjvO}_{2}$ also increased at extubation. But there was no significant difference between group $\mathrm{P}$ and group $\mathrm{S}$ during anesthesia induction and surgery (Figure 1).

Table I Characteristics of the patients

\begin{tabular}{llll}
\hline Characteristics & $\begin{array}{l}\text { Propofol } \\
\text { group }(\mathbf{n = 3 2})\end{array}$ & $\begin{array}{l}\text { Sevoflurane } \\
\text { group }(\mathbf{n = 3} \text { I) }\end{array}$ & P-value \\
\hline Sex (M/F) & $23 / 9$ & $23 / 8$ & 0.836 \\
Age (years) & $63.5 \pm 7.6$ & $64.2 \pm 8.3$ & 0.728 \\
Weight $(\mathrm{kg})$ & $59.4 \pm 10.5$ & $56.3 \pm 7.4$ & 0.182 \\
Height $(\mathrm{cm})$ & $165 \pm 6$ & $164 \pm 9$ & 0.605 \\
Hypertension & 3 & 5 & 0.421 \\
Diabetes & 0 & $\mathrm{I}$ & 0.306 \\
Ischemic heart disease & $\mathrm{I}$ & 3 & 0.286 \\
ASA class II/III & $30 / 2$ & $25 / 6$ & 0.118 \\
\hline
\end{tabular}

Note: Data presented as mean \pm SD.

Abbreviations: M, male; F, female; ASA, American Society of Anesthesiologists.
Table 2 Surgical data in the two groups

\begin{tabular}{llll}
\hline & $\begin{array}{l}\text { Propofol } \\
\text { group }(\mathbf{n}=\mathbf{3 2})\end{array}$ & $\begin{array}{l}\text { Sevoflurane } \\
\text { group }(\mathbf{n}=\mathbf{3} \mathrm{I})\end{array}$ & P-value \\
\hline Anesthesia time $(\mathrm{min})$ & $277.6 \pm \mathrm{I} 77.5$ & $289.7 \pm 106.6$ & 0.545 \\
Surgery time $(\mathrm{min})$ & $245.4 \pm \mathrm{II} 4 . \mathrm{I}$ & $248 . \mathrm{I} \pm 108.4$ & $0.58 \mathrm{I}$ \\
Blood loss $(\mathrm{mL})$ & $282.4 \pm 234.5$ & $255.0 \pm 313.4$ & 0.98 \\
Fluid $(\mathrm{mL})$ & $2,873 \pm \mathrm{I}, 00 \mathrm{I}$ & $3,250 \pm \mathrm{I}, 177$ & 0.33 \\
Norepinephrine $(\mu \mathrm{g})$ & 0 & $272.5 \pm 366.7$ & 0.0042 \\
Fentanyl $(\mathrm{mg})$ & $0.49 \pm 0.15$ & $0.46 \pm 0.13$ & 0.6537 \\
Morphine $(\mathrm{mg})$ & $36 \pm 7.9 \mathrm{I}$ & $37.8 \mathrm{I} \pm 6.5 \mathrm{I}$ & 0.8656 \\
\hline
\end{tabular}

Note: Data presented as mean \pm SD.

The $\mathrm{CBF} / \mathrm{CMRO}_{2}$ increased in group $\mathrm{S}$ during anesthesia induction at 1 hour, 2 hours, the end of surgery, and extubation, when compared to baseline. The $\mathrm{CBF} / \mathrm{CMRO}_{2}$ increased in group $\mathrm{P}$ at the end of surgery and extubation but did not change at the end of surgery, when compared to baseline. The $\mathrm{CBF} / \mathrm{CMRO}_{2}$ was significantly higher in group $\mathrm{S}$ than that in group $\mathrm{P}$ during anesthesia induction at 1 hour, 2 hours, and the end of surgery (Figure 2).

\section{SI00ß protein}

The level of S100 $\beta$ protein significantly increased at extubation and 1 day after surgery when compared to baseline in both groups $(P<0.05)$. However, there was no significant difference in the levels of S100 $\beta$ protein between group $\mathrm{P}$ and group $\mathrm{S}$ at baseline, after extubation, and day 1 following surgery $(P>0.05$; Table 4$)$.

\section{Discussion}

In this study, we compared the effects of propofol and sevoflurane on cerebral oxygenation and cognitive outcome in patients who underwent elective abdominal surgery. The results indicated that patients anesthetized with sevoflurane showed better cerebral oxygenation than those with propofol, and there was no significant difference in the $\mathrm{SjvO}_{2}$, incidence of POCD, and S100 $\beta$ protein levels between group S and group $\mathrm{P}$.

Table 3 MMSE and MoCA scores in the two groups

\begin{tabular}{lllll}
\hline & Test & $\begin{array}{l}\text { Propofol } \\
\text { group }(\mathbf{n = 3 2})\end{array}$ & $\begin{array}{l}\text { Sevoflurane } \\
\text { group }(\mathbf{n = 3} \text { I) }\end{array}$ & P-value \\
\hline Baseline & MMSE & $26.30 \pm 1.54$ & $26.50 \pm 2.21$ & 0.3948 \\
& MoCA & $22.44 \pm 3.12$ & $22.43 \pm 3.80$ & 0.8814 \\
Day I postsurgery & MMSE & $24.80 \pm 2.43$ & $25.93 \pm 2.46$ & 0.1767 \\
& MoCA & $19.40 \pm 4.98$ & $20.93 \pm 4.32$ & 0.5086 \\
Day 7 postsurgery & MMSE & $26.27 \pm 1.94$ & $26.36 \pm 2.68$ & 0.3400 \\
& MoCA & $21.40 \pm 4.24$ & $21.21 \pm 5.39$ & 0.8107 \\
\hline
\end{tabular}

Note: Data presented as mean \pm SD.

Abbreviations: MMSE, mini-mental state examination; MoCA, Montreal Cognitive Assessment. 


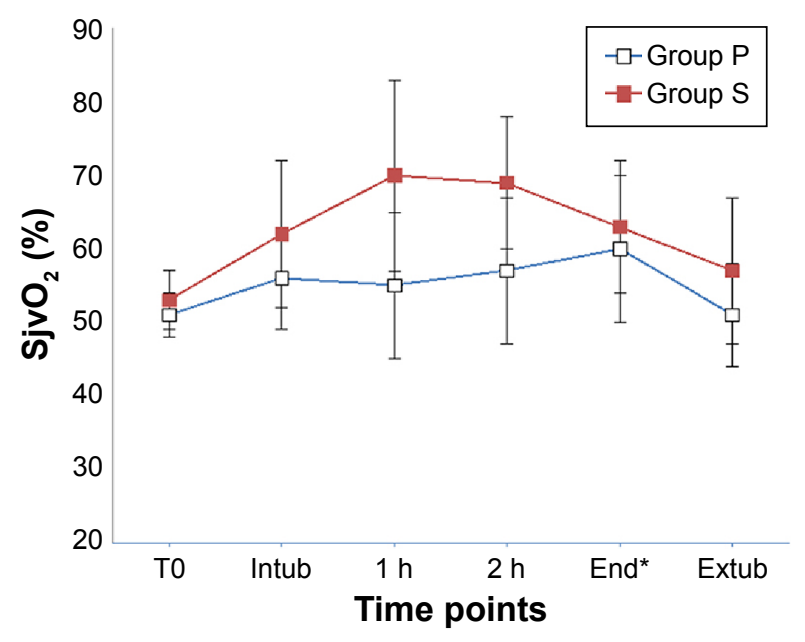

Figure I $\mathrm{SjVO}_{2}$ during anesthesia induction and surgery in different groups. Notes: The error bars indicate standard deviation. T0 is baseline before anesthesia induction. *End represents the end of the surgery.

Abbreviations: $\mathrm{SjvO}_{2}$, jugular venous bulb oxygen saturation; group $\mathrm{P}$, propofol group; group S, sevoflurane group; intub, intubation; extub, extubation.

POCD is a common postoperative complication that may reduce the life quality of patients and increase mortality. ${ }^{10}$ It was reported that cerebral oxygen desaturation during thoracic surgery could predict early POCD, ${ }^{11}$ was observed in many surgeries, ${ }^{12,13}$ and may be associated with POCD, delirium, and longer hospitalization. ${ }^{14,15}$ Furthermore, the cerebral oxygen desaturation or impairment may be related to the administration of anesthetics. ${ }^{6,7}$ General anesthetic propofol has been reported to reduce $\mathrm{CBF}$ in equivalent proportion to cerebral metabolism, while sevoflurane can reduce cerebral metabolism but not as much as propofol. ${ }^{8} \mathrm{SjvO}_{2}$ is

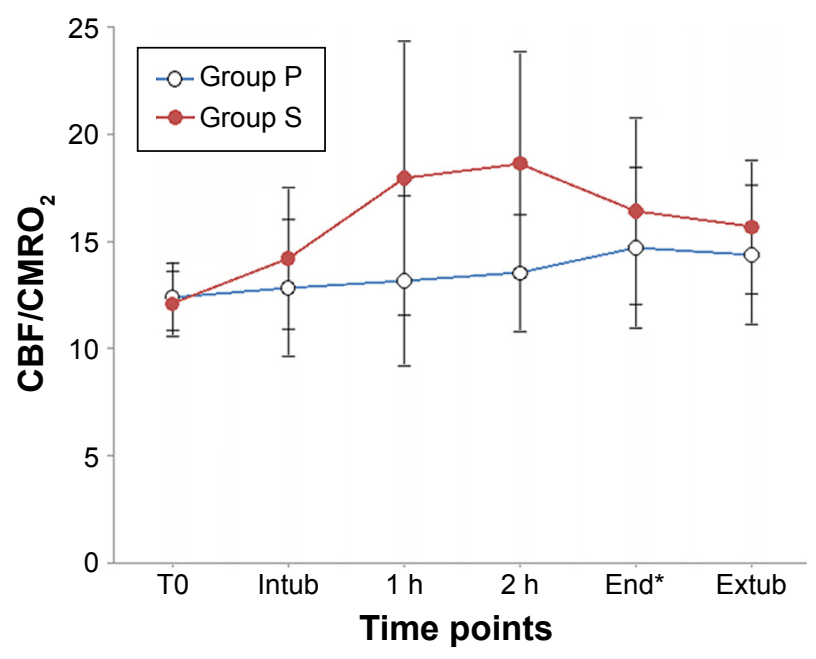

Figure $2 \mathrm{CBF} / \mathrm{CMRO}_{2}$ during anesthesia induction and surgery in different groups. Notes: The error bars indicate standard deviation. T0, baseline before anesthesia induction. *End represents the end of the surgery.

Abbreviations: $\mathrm{CBF} / \mathrm{CMRO}_{2}$, cerebral blood flow/cerebral metabolic rate of oxygen; group P, propofol group; group S, sevoflurane group; intub, intubation; extub, extubation.
Table 4 Changes in SI00 $\beta$ protein levels in the two groups

\begin{tabular}{lll}
\hline & $\begin{array}{l}\text { Propofol group } \\
(\mathbf{n}=\mathbf{3 2})\end{array}$ & $\begin{array}{l}\text { Sevoflurane group } \\
(\mathbf{n}=\mathbf{3 1})\end{array}$ \\
\hline Presurgery & $505.57 \pm 169.95$ & $502.38 \pm 149.35$ \\
Postsurgery** & $630.56 \pm 126.47^{*}$ & $648.29 \pm 142.34^{*}$ \\
Day I postsurgery & $536.46 \pm 200.84$ & $616.59 \pm 146.98$ \\
\hline
\end{tabular}

Notes: Data presented as mean $\pm \mathrm{SD}$. $* P<0.05$ versus presurgery. $* *$ Immediately after trachea extubation.

an indicator of global cerebral oxygen consumption and is independent of inhaled oxygen concentration during general anesthesia. ${ }^{16}$ It was reported that $\mathrm{SjvO}_{2}$ remained unchanged during mild-to-moderate hemodilution, but was significantly lower under propofol anesthesia when compared with those under sevoflurane/nitrous oxide anesthesia. ${ }^{17}$ These studies are consistent with the results of the present study showing that $\mathrm{SjvO}_{2}$ was increased at different time points. However, we did not find any significant difference between the two groups, suggesting that propofol and sevoflurane had similar effects on cerebral oxygen consumption.

Previous studies showed that, in total intravenous anesthesia with propofol-remifentanil, CBF decreased progressively with the decrease of cerebral electrical activity measured by bispectral index, while higher dose of sevoflurane increased the CBF despite a decrease in bispectral index value. ${ }^{18,19}$ These findings suggest the presence of an intrinsic dose-dependent vasodilatory effect of sevoflurane, which might have positive influence on patients with impaired baseline cerebral oxygenation. In the present study, the cerebral oxygenation was improved with significant increase in $\mathrm{CBF} / \mathrm{CMRO}_{2}$ following sevoflurane inhalation. In contrast, $\mathrm{CBF} / \mathrm{CMRO}_{2}$ only demonstrated a slight increase after intravenous anesthesia of propofol, suggesting that propofol has no significant influence on metabolic coupling, which was consistent with previous studies. ${ }^{20-22}$ However, it has been reported that, during carotid endarterectomy, propofol could be advantageous in cognitive function over sevoflurane, ${ }^{23}$ which is inconsistent with the present study showing that cognition was not significantly affected in both groups. This inconsistency remains to be further studied.

$\mathrm{S} 100 \beta$ is a $21 \mathrm{kDa}$ calcium-binding protein primarily localized in astrocytes and associated with POCD as a neurodegenerative biomarker. ${ }^{24,25}$ A study in mice showed that propofol and isoflurane increased the level of S100 $\beta$ and neuronal apoptosis but had no significant effect on cognition. ${ }^{25}$ However, the present study found that both groups showed normal S100 $\beta$ level and cognitive functions, suggesting that propofol and sevoflurane, at the dosage used in the present study, had no significant effect on cognition in the 
short term. Therefore, there is insufficient evidence to show that sevoflurane is better than propofol in those patients with impaired cerebral oxygenation. The comprehensive effects of general anesthetics such as propofol and sevoflurane on brain cells require further detailed studies.

\section{Conclusion}

The present study demonstrated that sevoflurane improved the cerebral oxygenation of patients with impaired cerebral oxygenation when compared to propofol and that both sevoflurane and propofol have no significant effect on postoperative neurocognitive function in the short term.

\section{Disclosure}

The authors report no conflicts of interest in this work.

\section{References}

1. Youngblom E, DePalma G, Sands L, et al. The temporal relationship between early postoperative delirium and postoperative cognitive dysfunction in older patients: a prospective cohort study. Can J Anaesth 2014;61:1084-1092.

2. Mashour GA, Woodrum DT, Avidan MS. Neurological complications of surgery and anaesthesia. Br J Anaesth. 2015;114:194-203.

3. Krenk L, Kehlet H, Bæk Hansen T, et al. Cognitive dysfunction after fasttrack hip and knee replacement. Anesth Analg. 2014;118:1034-1040.

4. Evered L, Scott DA, Silbert B, et al. Postoperative cognitive dysfunction is independent of type of surgery and anesthetic. Anesth Analg. 2011; 112:1179-1855.

5. Monk TG, Weldon BC, Garvan CW, et al. Predictors of cognitive dysfunction after major noncardiac surgery. Anesthesiology. 2008;108: $18-30$.

6. Liu J, Wang P, Zhang X, et al. Effects of different concentration and duration time of isoflurane on acute and long-term neurocognitive function of young adult C57BL/6 mouse. Int J Clin Exp Pathol. 2014; 7(9):5828-5836.

7. Ballard C, Jones E, Gauge N, et al. Optimised anaesthesia to reduce post operative cognitive decline (POCD) in older patients undergoing elective surgery, a randomised controlled trial. PLoS One. 2012;7(6): e37410.

8. Kaisti KK, Metsähonkala L, Teräs M, et al. Effects of surgical levels of propofol and sevoflurane anesthesia on cerebral blood flow in healthy subjects studied with positron emission tomography. Anesthesiology. 2002;96:1358-1370.

9. Hong SW, Shim JK, Choi YS, et al. Prediction of cognitive dysfunction and patients' outcome following valvular heart surgery and the role of cerebral oximetry. Eur J Cardiothorac Surg. 2008;33(4):560-565.

10. Silbert BS, Evered LA, Scott DA. Incidence of postoperative cognitive dysfunction after general or spinal anaesthesia for extracorporeal shock wave lithotripsy. Br J Anaesth. 2014;113:784-791.
11. Tang L, Kazan R, Taddei R, et al. Reduced cerebral oxygen saturation during thoracic surgery predicts early postoperative cognitive dysfunction. Br J Anaesth. 2012;108:623-629.

12. Liao R, Li J, Liu J. Volatile induction/maintenance of anaesthesia with sevoflurane increases jugular venous oxygen saturation and lumbar cerebrospinal fluid pressure in patients undergoing craniotomy. Eur J Anaesthesiol. 2010;27:369-376.

13. Soeding PF, Hoy S, Hoy G, et al. Effect of phenylephrine on the haemodynamic state and cerebral oxygen saturation during anaesthesia in the upright position. Br J Anaesth. 2013;111:229-234.

14. Slater JP, Guarino T, Stack J, et al. Cerebral oxygen desaturation predicts cognitive decline and longer hospital stay after cardiac surgery. Ann Thorac Surg. 2009;87:36-44.

15. Gleason LJ, Schmitt EM, Kosar CM, et al. Effect of delirium and other major complications on outcomes after elective surgery in older adults. JAMA Surg. 2015;150(12):1134-1140.

16. Schell RM, Cole DJ. Cerebral monitoring: jugular venous oximetry. Anesth Analg. 2000;90:559-566.

17. Yoshitani K, Kawaguchi M, Iwata M, et al. Comparison of changes in jugular venous bulb oxygen saturation and cerebral oxygen saturation during variations of haemoglobin concentration under propofol and sevoflurane anaesthesia. Br J Anaesth. 2005;94:341-346.

18. Conti A, Iacopino DG, Fodale V, et al. Cerebral haemodynamic changes during propofol-remifentanil or sevoflurane anaesthesia: transcranial Doppler study under bispectral index monitoring. Br J Anaesth. 2006;97: 333-339.

19. Dahaba AA, Xue JX, Hua Y, et al. The utility of using the bispectral index-Vista for detecting cross-clamping decline in cerebral blood flow velocity. Neurosurgery. 2010;67:ons102-ons107.

20. Klein KU, Fukui K, Schramm P, et al. Human cerebral microcirculation and oxygen saturation during propofol-induced reduction of bispectral index. Br J Anaesth. 2011;107(5):735-741.

21. Evered LA, Silbert BS, Scott DA, et al. Preexisting cognitive impairment and mild cognitive impairment in subjects presenting for total hip joint replacement. Anesthesiology. 2011;114:1297-1304.

22. Jeong $\mathrm{H}$, Jeong $\mathrm{S}$, Lim HJ, et al. Cerebral oxygen saturation measured by near-infrared spectroscopy and jugular venous bulb oxygen saturation during arthroscopic shoulder surgery in beach chair position under sevoflurane-nitrous oxide or propofol-remifentanil anesthesia. Anesthesiology. 2012;116:1047-1056.

23. Kalimeris K, Kouni S, Kostopanagiotou G, et al. Cognitive function and oxidative stress after carotid endoarterectomy: comparison of propofol to sevoflurane anesthesia. J Cardiothorac Vasc Anesth. 2013;27: $1246-1252$.

24. Stamataki E, Stathopoulos A, Garini E, et al. Serum S100B protein is increased and correlates with interleukin 6, hypoperfusion indices, and outcome in patients admitted for surgical control of hemorrhage. Shock. 2013;40:274-280

25. Yang B, Liang G, Khojasteh S, et al. Comparison of neurodegeneration and cognitive impairment in neonatal mice exposed to propofol or isoflurane. PLoS One. 2014;9(6):e99171.
Therapeutics and Clinical Risk Management

\section{Publish your work in this journal}

Therapeutics and Clinical Risk Management is an international, peerreviewed journal of clinical therapeutics and risk management, focusing on concise rapid reporting of clinical studies in all therapeutic areas, outcomes, safety, and programs for the effective, safe, and sustained use of medicines. This journal is indexed on PubMed Central, CAS,

\section{Dovepress}

EMBase, Scopus and the Elsevier Bibliographic databases. The manuscript management system is completely online and includes a very quick and fair peer-review system, which is all easy to use. Visit $\mathrm{http}: / / \mathrm{www}$.dovepress.com/testimonials.php to read real quotes from published authors. 